\title{
SAÚDE COLETIVA: HISTÓRIA DE UMA IDÉIA E DE UM CONCEITO
}

Everardo Duarte Nunes *

Resumo: 0 presente trabalho procura resgatar de forma sintética a trajetória histórica e conceitual da "Saúde Coletiva", evidenciando as suas raízes nos projetos preventivistas e da medicina social. Estes projetos, que se estenderam a partir dos anos 50 e que culminam com a idéia da chamada "Saúde Coletiva", apresentam aspectos que os diferenciam na apreensão do social e do coletivo. Ao tratar especificamente da idéia de uma Saúde Coletiva, o texto aponta para a sua tríplice dimensão: como corrente de pensamento, como movimento social e como prática teórica.

Ao recuperar historicamente as idéias e os momentos que, num passado não muito distante, forneceram as bases para a emergência de um projeto denominado de saúde coletiva, podemos situar, para a América Latina, como data de referência inicial, a segunda metade dos anos 50 , embora a sua trajetória não seja a mesma para todos os paises latino-americanos. Assim, a partir de um núcleo inicial bastante homogêneo, para o Brasil a especificidade que iria adquirir a chamada Saúde Coletiva tornar-se-ia bastante evidente. Dessa forma, a fase que se estende por cerca de quinze anos, e que denomino de "pré-saúde coletiva", foi marcada pela instauração do "projeto preventivista". A segunda fase, até o final dos anos 70 , não isola os ideais preventivistas, mas reforça a perspectiva de uma "medicina social", e, a partir de 80 até a atualidade, vai se estruturando o campo da "saúde coletiva". Lembramos que a divisão cronológica adotada é feita a partir

- Professor e pesquisador - Faculdade de Ciências Módicas/UNICAMP. 
de um conjunto de eventos que marcam uma mudança de perspectiva em relação ao social e ao coletivo, e mesmo sendo abordagens diferentes, que não podem ser confundidas, é possivel encontrar no período mais recente aspectos das etapas anteriores.

Como tem sido abordado por estudiosos desse período, a emergência desses projetos reflete, de um modo geral, o contexto sócio-econômico e políticoideológico mais amplo, como também as sucessivas crises, presentes tanto no plano epistemológico, como das práticas em saúde e da formação de recursos humanos.

De certa forma, numa linguagem um pouco diferente, mas que me parece dentro deste raciocínio, MENÉNDEZ (1992) escreve:

"Periodicamente se planeja a nível social geral a revisão de conceitos, valores e estratégias que se consideram chaves a partir de uma perspectiva global. Também se faz o mesmo a nível de cada disciplina, ainda que de forma mais pontual e especifica. Geralmente se sustenta que tais revisões obedeceriam, no primeiro caso, a situações de crises pensadas não somente em termos económicos-politicos mas também em termos ideológicos-culturais, enquanto no segundo caso obedeceria ao reconhecimento da inviabilidade ou limitaçóes dos paradigmas dominantes ou das tendéncias hegemónicas que orientem o desenvolvimento de uma disciplina especifica".

Assim, quando se analisa a emergência de um projeto preventivista latino-americano, que tem suas origens na segunda metade dos anos 50 , com as célebres e conhecidas reuniōes que se realizaram no Chile e México, o que já se diagnosticava era a crise de uma determinada medicina, tanto em sua teoria, como em sua prática. É interessante que as reformas que vão ser defendidas aparecem 
estreitamente vinculadas a um projeto pedagógico, e não de reforma direta das práticas médicas. Tanto assim, que o grande saldo desse periodo é a inclusão, no curso de graduação em medicina, de disciplinas e temas associados à epidemiologia, ciências da conduta, administração de serviços de saúde, bioestatística. Procurava-se, dessa forma, ao criticar a biologização do ensino, calcado em práticas individuais e centradas no hospital, não somente introduzir outros conhecimentos, mas fornecer uma visão mais completa do individuo. A citada integração bio-psicossocial tem aqui as suas origens, e o modelo da medicina integral, numa apropriação da expressão "comprehensive medicine", aparece na versão latino-americana, colocando ênfase na medicina de família "integrada" no plano da comunidade. Se, no plano do conhecimento, é o momento de dar espaço a alguns conceitos sociológicos, antropológicos, demográficos, epidemiológicos e ecológicos, no plano político-ideológico, o projeto preventivista se expressa na chamada "medicina comunitária" e seus desdobramentos nos programas extra-muros.

Nesse momento, quando se estabelecem as discussões sobre um projeto alternativo, o mundo vivia um periodo de grandes transformações conseqüentes do término da 2a. Grande Guerra. Junto à expansão econômica, ocorreu uma intensificação da produção industrial manufatureira, principalmente em alguns países como Argentina, Brasil, Chile e México. Implantava-se um novo modelo de acumulação, baseado na substituição de importações; ampliava-se a participação estatal no processo de acumulação, ao aumentar a produtividade da força de trabalho. As formas adotadas para isto serão a seguridade social e os programas de saneamento ambiental nas zonas agro-exportadoras. Entra em voga neste periodo o conceito de controle e assiste-se à progressiva utilização dos antibióticos e técnicas cirúrgicas e a consolidação da confiança na atenção médica individualizada. Fase áurea das teorias desenvolvimentistas e da idéia do círculo vicioso pobreza-doença, transformada em "causação circular", por Gunnar 
Myrdal. Na política assiste-se, em meados dos 50 , à queda de alguns governos populistas: Peron, Vargas, Arbenz. (NUNES, 1991).

É neste cenário que se discute e se tenta implantar a idéia de um campo de saber e práticas denominado de Medicina Preventiva e Social, cujos principais contomos traçamos acima, e que se converte em um movimento que se estende até os anos 70 . Também, meados de 60, é quando se instaura na América Latina a questão do planejamento em saúde veiculada pela proposta CENDES/OPS, que, dentro de uma visão economicista, fixava como básica a determinação da relação custo/benefício. Somente uma década mais tarde este marco do planejamento em saúde será revisitado. Como foi assinalado, ao se instaurar o projeto preventivista estabelecia-se um projeto pedagógico, diferente do até então existente e que tivera seu principal modelo na formação de sanitaristas, via saúde pública. Lembre-se que a criação de um programa de residência médica na Faculdade de Medicina de Ribeirão Preto, em 1962, pode ser citado como pioneiro na formação de um profissional com base na integração das ações preventiva e curativa.

Até final dos anos 60 e início dos 70 , inclusive sob o impacto da Reforma Universitária (1968), aparecem iniciativas que procuram reatualizar a formação de recursos, mas também é na década de 70 que se verifica o aparecimento de alguns trabalhos que estabelecem uma contundente critica às formulações e às práticas, que na década anterior haviam se voltado contra o modelo médico hegemônico, assim como se discutem as diferenças entre medicina preventiva, medicina social e saúde pública (GARCíA, 1972, AROUCA, 1975). A própria Organização Pan Americana da Saúde, que havia estimulado a difusão de um pensamento preventivista, assume em documento de 1974 que, do ponto de vista estrutural, os objetivos dos Seminários de 1955 e 1956 haviam sido alcançados, com a introdução de disciplinas de medicina preventiva, mas que as 
reformas preconizadas não haviam se integrado no processo global da escola médica, e que a integração com a comunidade estava baseada em esquemas artificiais e desvinculados dos serviços existentes na comunidade. Enfaticamente, expunha que "as ambiciosas metas de obter a transformaçāo das práticas de saúde, em especial da atenção médica, mediante a formação de um profissional capacitado para realizar essas mudanças, năo haviam se concretizado..." (OPS, 1976).

O trabalho de AROUCA (1975), de exatamente vinte anos atrás, irá estabelecer uma profunda análise crítica do projeto preventivista, e, entre outros pontos, assinalará: "A Medicina Preventiva realiza um trabalho de delimitação, que por um lado afirma a sua identidade e a diferencia da própria medicina e por outro lado estabelece suas diferenças com a Saúde Pública e a Medicina Social". Nessa tese, o autor recuperava, entre outros pontos, a discussão que os Departamentos de Medicina Preventiva e Social haviam travado no inicio dos anos 70 , procurando redefinir o campo de trabalho que indistintamente tratava 0 preventivo e o social.

Sem dúvida, o repensar do que havia até então sido proposto e realizado foi decorrência de diversos fatores, e que podem ser vistos nos diversos posicionamentos relacionados não somente à formação de profissionais, mas aos conteúdos dessa formação, às funções que estavam sendo preenchidas, que se apresentavam como extremamente racionalizadoras, e pelos problemas que a sociedade civil enfrentava naquele momento.

Abria-se, na periodização que adotamos, o momento da Medicina Social propriamente dita.

Mas qual era a proposta dos órgãos internacionais sobre a Medicina Social, que iria caracterizar um segundo momento nessa trajetória de conformar um 
campo de práticas e saberes? E do ponto de vista nacional, quais eram as novas definições?

Sem pretender traçar uma arqueologia da Medicina Social, cujas origens européias se estendem desde a segunda metade do século $X I X$, quando a expressão foi cunhada na França em 1848, assinale-se que a idéia reaparece em 1952, em reunião convocada pela OMS, em Nancy, sem que se possa deixar de lado que uma data, 1948, seria da maior importância, pois com ela abria-se um novo ciclo em relação à atenção à saúde, com a criação do Nacional Health Service, modelo e horizonte para muitos serviços de saúde. Quanto à reunião da OMS, o relator sobre o tema foi Sigerist (ROEMER, 1960). Naquele momento, e participando do Comitê de Especialistas sobre Profesional and Technical Education of Medical and Auxiliary Personnel, o já famoso historiador da Medicina não somente fez uma síntese dos progressos até então alcançados pela medicina, como chamou a atenção para o papel do médico que, segundo ele, deveria se tornar um "social physician". De outro lado, cumpria às escolas médicas integrar em seus currículos a dimensão do social. Para tal, a inclusão da economia e da sociologia da medicina, para as quais sugere um programa, seriam fundamentais.

A retomada de idéias sobre a Medicina Social seria objeto de documento da OPS, de 1974, quando esse organismo assume que o objeto da medicina social deve ser entendido como "o campo de práticas e conhecimentos relacionados com a saúde como sua preocupação principal e estudar a sociedade, analisar as formas correntes de interpretação dos problemas de saúde e da prática médica" (OPS, 1976).

Basicamente, o quadro conceitual que fornecia as bases para repensar esse campo de práticas era o de considerar "que em cada formaçáo social concreta a educação cumpre um papel fundamental na reprodução da 
organização dos serviços de saúde e se cristaliza na reatualização e preservação das práticas específicas, tanto nas dimensōes do conhecimento quanto nas técnicas e no conteúdo ideológico". Outro ponto destacava: "É a própria estrutura da atenção médica que exerce um papel dominante através da estrutura do mercado de trabalho e das condições que circunscrevem a prática médica". Essa forma mecânica de determinação da prática sobre o ensino não passou desapercebida para alguns estudiosos, que apontariam a necessidade de que se preservasse algum grau de autonomia à universidade (BOJALIL \& GARCIA, 1981).

No ideário nacional, e até com certa precedência em relação às discussões internacionais, pois já em 1970 estabelecia intensa discussão sobre os caminhos da Medicina Preventiva, existia tanto a posição que rastreava nos conceitos da Medicina Social européia os seus pressupostos - enfatizando os niveis de prevenção através das práticas individuais ou coletivas da atenção médica, como a conceituação adotada por outros que tomava a Medicina Social "como o estudo da dinámica do processo saúde-doença nas populações, suas relações com a estrutura de atenção médica, bem como das relações de ambas com o sistema social global, visando à transformação destas relaçōes para a obtenção dentro dos conhecimentos atuais, de níveis máximos possiveis de saúde e bem-estar das populações" (AROUCA, 1975).

Em trabalho escrito em 1973, o Prof. Guilherme Rodrigues da Silva irá exatamente retomar a questão da distinção entre os conceitos de Medicina Preventiva e Social, assinalando que "... alguns departamentos de Medicina Preventiva passaram a adotar, tendencialmente uma posição potencialmente mais inovadora, uma posição de crítica construtiva da realidade médico-social e da prática da medicina, fundamentada bem mais no modelo de medicina social do que no modelo original de Medicina Preventiva" (SILVA, 1973) 
Ao citar este trabalho, não se pode deixar de mencionar que os anos iniciais da década de 70 serão extremamente férteis em discussões teóricas sobre as relações saúde-sociedade; por exemplo, o Seminário realizado pela OPS, em Cuenca (Equador), em 1972, quando emerge com força o paradigma marxista de análise, especialmente na vertente trazida por Althusser. Em realidade, esse período foi marcado pela inquietação teórica, não se esquecendo, também, da importância que passaria a ter a corrente estruturalista, via Foucault e Levi-Strauss; também é a época em que se veiculam as discussões no campo da psiquiatria, com Basaglia, Castel, Laing e Cooper. De outro lado, também se assumia que a grande meta era garantir, através da intervenção do Estado, a saúde como um direito inalienável para todos os individuos. A extensão dos serviços e a racionalização no uso dos recursos são definidos como fundamentais, embora presentes num contexto financeiro que se caracteriza como de crise fiscal e de pessimismo com os efeitos do chamado "milagre brasileiro". Num cenário que tinha sido marcado pelas forças de repressão e pela piora crescente dos indicadores sócio-econômicos e de saúde, paulatinamente ia-se tentando construir um campo de práticas e saberes transformadores. Como assinala LAURELL (1986), assistia-se, já no final dos anos 60, ao início da crise do que se pode chamar do modelo de Saúde Pública desenvolvimentista, que havia postulado que um dos efeitos do crescimento econômico seria a melhoria das condições de saúde. Não se trata de apontar com números e dados a deterioração dessas condições de saúde, especialmente no que se refere à desnutrição e à emergência de novos problemas, como o dos acidentes de trabalho e das doenças crônico-degenerativas, mas assinalar que o perfil de morbi-mortalidade de então já apontava para uma "conformação da problemática da saúde coletiva que abarcava o "pior dos mundos", com uma mescla da patologia da "pobreza" e da patologia da "riqueza" (LAURELL, 1986). 
Este novo cenário provocará, como já assinalado, a busca de um novo paradigma. Nesse sentido, a síntese escrita por AROUCA (1975) é extremamente feliz ao captar a proposta da Medicina Social: "... uma tentativa de redefinir a posição e o lugar dos objetos dentro da medicina, de fazer demarcaçóes conceituais, colocar em questão quadros teóricos, enfim, trata-se de um movimento ao nivel da produção de conhecimentos que, reformulando as indagaçōes básicas que possibilitaram a emergência da Medicina Preventiva, tenta definir um objeto de estudo nas relações entre o biologico e 0 psicossocial. A Medicina Social, elegendo como campo de investigaçăo estas relações, tenta estabelecer uma disciplina que se situa nos limites das ciéncias atuais" (AROUCA, 1975). Não se esqueça, também, que, ao apontar a crise na geração de conhecimentos, $\circ$ horizonte que se vislumbrava era $\circ$ de instaurar novas práticas. Os estudiosos assinalam que a visibilidade social que a problemática de saúde adquire nesse período deve-se em grande parte aos movimentos sociais populares, tanto o operário como o universitário. A instauração de uma outra forma de pensar o planejamento em saúde, diferente da proposta de 1965, estará presente no documento que a OPS publica em 1975, aparecendo a expressão "Formulación de politicas de saúde", título do documento elaborado pelo grupo do Centro Panamericano de Planificación en Salud.

Estava aberto o caminho para que se redefinisse, no âmbito da formação, o estabelecimento de cursos que pudessem realizar um salto qualitativo em termos do ensino e da pesquisa em moldes acadêmicos, semelhantes aos já existentes em outros campos da medicina; ou seja, formando mestres e doutores em medicina preventiva, saúde pública e medicina social. Em realidade, os primeiros cursos de pós-graduação stricto sensu foram criados em 1970, na Faculdade de Saúde Pública da USP; em 1971 na Faculdade de Medicina de Ribeirão Preto; em 1973 na Faculdade de Medicina da USP e na Faculdade de Medicina da Universidade Federal da Bahia. Em 1974 iniciava-se o mestrado em 
medicina social do Instituto de Medicina Social na Universidade do Estado do Rio de Janeiro, que "visava a formar um médico com conhecimentos nas áreas de epidemiologia, planejamento e ciências sociais de tal modo entrelaçados que lhe permitissem uma ação polivalente, crítica e transformadora". (BEZERRA Jr. \& SAYD, 1993) e que permanece praticamente sem alterações até 1986, quando é substituído pelo Mestrado em Saúde Coletiva.

Foi também na segunda metade dos anos 70 que se instalaram os cursos regionalizados de Saúde Pública, visando preparar profissionais que atendessem aos pressupostos da extensão de cobertura na rede básica de serviços. Mas, voltando à pós-graduação stricto sensu e sem pretender uma história desses cursos, lembre-se que em suas origens ela se apresenta como a possibilitadora do estabelecimento de um espaço que pudesse, como apontam BEZERRA Jr. \& SAYD (1993), atingir "um duplo alvo: a formação teórica e a crítica politica".

Em verdade, o final dos anos 70 irá confirmar a crise que se estabelecera na segunda metade deste periodo, quando a tendência recessiva da economia dos países latino-americanos se acentua, com o agravamento do processo inflacionário, o aumento da dívida externa, do desemprego e do déficit fiscal, marcando de forma negativa os niveis de saúde e impondo mais uma vez uma tomada de posição frente às questões de saúde. No nivel internacional, instala-se o discurso da Atenção Primária; no nível nacional, vai se consolidando uma tomada de posição frente ao problema sanitário e à aglutinação dos diversos segmentos que tratavam da medicina preventiva, medicina social, saúde pública. Além da instalação de cursos de pós-graduação, formam-se duas organizações, o CEBES e a ABRASCO, que, a partir desse momento, 1976 e 1978, irão se estabelecer como espaços de resistência e análise crítica da situação de saúde e das políticas sanitárias. Concretizava-se, também, no final de 70 , através da 
Resolução 08/79 a regulamentação da Residência em Medicina Preventiva e Social, como uma das áreas básicas do programa de residência médica. Os desdobramentos desses programas e as resoluções posteriores que revogaram a de número $08 / 79$, sobretudo a Resolução $16 / 81$ que cria duas alternativas aos programas - o modelo da Medicina de Familia - denominado de Medicina Geral e Comunitária, e o modelo da Saúde Coletiva - e que fazem parte da história da Residência e de suas resistências, não serão aqui tratadas, mas constituem momentos importantes desse movimento.

Dessa forma, fatores estruturais e conjunturais associavam-se para marcar a premência de um repensar a saúde em uma dimensão ampliada.

Entrávamos, assim, segundo a periodização que adotei neste trabalho, na terceira fase - a da Saúde Coletiva.

Vejamos um pouco sua história cronológica. A idéia de uma área denominada Saúde Coletiva é tratada em dois momentos, no ano de 1978: no I Encontro Nacional de Pós-graduação em Saúde Coletiva, realizado em Salvador, Bahia e, na Reunião sub-Regional de Saúde Pública da Organização Panamericana da Saúde/Associación Latinoamericana de Escuelas de Salud Pública (OPASIALESP), realizada em Ribeirão Preto; ambas tiveram como objetivo redefinir a formação de pessoal para o campo da saúde. Para isso, sentia-se a necessidade da existência de uma instituição que pudesse congregar, através de uma associação, os interesses das instituições formadoras num momento em que se sentia o esgotamento de uma determinada orientação, a da saúde pública clássica e a da medicina social. Isto se concretiza em dezembro de 1979, quando é criada a ABRASCO. Voltada para a formação em nivel de pós-graduação, ela assume que esta formação deveria ser orientada por "um processo gerador de análise critica do setor saúde na realidade social em que se insere; seja 
potencialmente capaz de influir no campo da docéncia, pesquisa e prestação de serviços". Afirma, ainda, o documento preliminar que: "Em termos de conteúdo programático, a Associação reconhece que se deva estabelecer um adequado equilíbrio entre os conteúdos técnicos e teórico-conceituais, entre o "biológico" e o "social", entre o "operacional" e o "crítico", como forma de evitar o "tecnicismo" e o "biologismo" presentes na tradição do ensino da área de Saúde Coletiva" (ABRASCO, 1982).

Mais do que ser conformada pelo somatório dos diversos programas das instituições formadoras que carregavam os seus referenciais preventivistas, de medicina social e de saúde pública, a saúde coletiva passa a se estruturar como um campo de saber e prática. O acúmulo de experiências e o exercicio crítico e politico estão nas bases dessa idéia que vai se fortalecendo na medida em que encontra nas práticas teóricas o solo que a fundamenta. Assim, vejo a saúde coletiva como corrente de pensamento, movimento social e prática teórica. Sem dúvida, esta formulação que se evidencia progressivamente a partir da segunda metade dos anos 70 já era percebida por Cecilia Donnangelo (1983), que, em seu último trabalho, preparado em colaboração com Oswaldo de Campos e apresentado em dezembro de 1981 no Seminário sobre Saúde Pública, organizado pela FUNDAP, procurava estabelecer "uma delimitação aproximada do campo, nāo através de definições formais e sem referência à especificidade que adquire na sociedade brasileira, determinado conjunto de práticas relacionadas à questảo da saúde". Como delimitar esse campo? Para a autora, "Essa multiplicidade de objetos e de áreas de saber correspondentes - da ciência natural à ciência social - não é indiferente à permeabilidade aparentemente mais imediata desse campo à inflexóes econômicas e políticoideológicas. O compromisso, ainda quando genérico e impreciso, com a noçāo de coletivo, implica a possibilidade de compromissos com manifestaçōes particulares, histórico-concretas desse mesmo coletivo, dos 
quais a medicina "do individuo" tem tentado se resguardar através do especifico estatuto da cientificidade dos campos de conhecimento que a fundamentam".

Ao tomarmos como ponto de maior inflexão de um pensamento de saúde coletiva a segunda metade dos anos 70 , não ignoramos a importância que tiveram alguns pensadores como Wilson Fadul, Carlos Gentile de Mello, Samuel Pessoa, que "transitavam no campo da formulaçáo da política e da investigação sócio-sanitaria", como è muito bem lembrado por COSTA (1992), em anos anteriores ao momento citado. Da mesma forma, especificamente em relação às contribuiçōes das ciências sociais, mostramos (NUNES, 1985; NUNES, 1991) também, como há antecedentes, desde os anos 40 , de investigadores que procuraram pesquisar "fatores socio-culturais da saúde". Citem-se, especialmente, dois antropólogos, Charles Wagley e Kalervo Oberg, que trabalharam junto ao Serviço Especial de Saúde Pública no estudo de comunidades para subsidiar trabalhos de educação e planejamento. Sem dúvida, estes antecedentes de estudos e ações são importantes, embora em sua maioria se limitassem a estudos de casos. Será, porém, a partir da análise crítica, em particular da corrente funcionalista da sociologia, no início dos anos 70 , que se estabelece um repensar das categorias analíticas que poderiam embasar a análise da saúde, trazendo para as pesquisas o referencial marxista, que se tomou fundamental para a estruturação teórica do campo da saúde coletiva. São marcantes os trabalhos de AROUCA (1975), DONNANGELO (1976) e, em outros dois paises da América Latina - Equador, com os trabalhos iniciais de Jaime Breilh, e, no México, Cristina Laurell. Se a produção de conhecimento, engendrada através das ciências sociais não é a única vertente que deu origem à saúde coletiva, como salienta COSTA (1992), não se pode minimizar a sua importância. Para este autor, "Essas preocupaçóes téricas ou de procedimentos foram condiçóes necessárias, porém não sufficientes para explicar a enorme repercussáo que o 
campo das ciências sociais teve na saúde coletiva". Retomo, portanto, neste ponto, como já foi assinalado, que entendo a saúde coletiva emergindo tanto como corrente de pensamento, cuja originalidade a distanciava, até recentemente, das experiências de outros países latino-americanos; como movimento social, que se articulou a um conjunto de condições políticas e institucionais, inclusive contando com substancial apoio financeiro para projetos (período de 1975-1986); e como prática teórica.

São muitos os aspectos que podem ser retomados nessas três dimensões mas que não cabem no espaço desta apresentação, inclusive a discussão do conceito de coletivo que exigiria maior aprofundamento. Porém, não se pode deixar de citar duas palavras rápidas. Como escreve $\mathrm{COHN}$ (s.d.), esse "novo cliente" - o coletivo, que não era desconhecido desde o final do século XIX, ressurge de maneira singular. Resumidamente, três são as perspectivas centrais apontadas pela autora: 1) que o coletivo irá se impor para a medicina, tanto para a prática curativa como de prevenção - "as práticas de saúde se dão sobre e no coletivo ao mesmo tempo que passam a se configurar como práticas coletivas de saúde"; 2) que a apreensão do coletivo apresenta especificidades próprias tanto para sua quantificação, como para a sua explicação; 3) que o coletivo é dinâmico, produto das relações sociais e que, ao se submeterem às suas regras, os individuos se submetem ativamente.

Penso que este dimensionamento do coletivo é correto, e acrescento que a sua historicização é fundamental; pois, dessa forma, pode-se reconhecer a sua existência como fato e acontecimento, impondo que a sua apreensão seja resultado de um caminho que encontre na epidemiologia, de um lado, e nas ciências humanas, de outro, as bases para a contínua construção do seu objeto. 
Construção esta que não tem sido alheia às rápidas transformações que se fizeram sentir a partir dos anos 80 , que se adensaram em seu final e com grande impacto nos atingem em anos recentes, e que imprimirão novas marcas na saúde coletiva, tanto no campo epistemológico, como das práticas, da formação, e do aparecimento de "novas" subáreas. Sem dúvida, como aponta FRANCO (1994), a iniquidade será o maior saldo vermelho no balanço sócio-sanitário da humanidade, no final deste milênio. Com a iniquidade expressa numa concentração de renda cada vez maior e sua tradução na pobreza em cifras que se elevam continuamente, crescem a fome, a má nutrição e a desnutrição. Acrescente-se à violência que se expande gerando a inseguridade social, o terceiro aspecto, o da deterioração do ambiente. Com sérios problemas sociais e sanitários somados à não efetivação das reformas dos sistemas de saúde preconizadas no final dos 80 , e mesmo com o crédito positivo da crescente mobilização social, a pauta da saúde coletiva torna-se mais extensa a cada dia que passa.

Fundamentando-se na interdisciplinaridade como possibilitadora da construção de um conhecimento ampliado da saúde e na multiprofissionalidade como forma de enfrentar a diversidade interna ao saber/fazer das práticas sanitárias, a saúde coletiva, no plano concreto dos conteúdos a serem transmitidos, necessita, atualmente, pensar o geral e o especifico. Ou seja, sem perder o núcleo central que a legitima e a distingue como área - de saber, de reflexão e crítica do social/coletivo - estar atenta para a formação de determinadas áreas de concentração.

Não fugindo da sua vocação, a saúde coletiva - constituida nos limites do biológico e do social - ainda continua a ter pela frente a tarefa de investigar, compreender e interpretar os determinantes da produção social das doenças e da organização social dos serviços de saúde, tanto no plano diacrônico como sincrônico da história. Ou, como apontam outros autores (BIRMAN, 1991), a saúde 
coletiva ao introduzir as ciências humanas no campo da saúde, reestrutura as coordenadas desse campo, trazendo para o seu interior as dimensões simbólica, ética e política, o que somente poderá revitalizar o discurso biológico.

\section{REFERÊNCIAS BIBLIOGRÁFICAS}

1.ABRASCO. Documento preliminar de princípios básicos. In: Ensino da saúde pública, medicina preventiva e social no Brasil. Rio de Janeiro, ABRASCO 1982:100-17.

2.AROUCA, A. S. S. O dilema preventivista: contribuição para a compreensão e crítica da medicina preventiva. Campinas, 1975. [Tese de Doutorado, Faculdade de Ciências Médicas da UNICAMP]

3.BEZERRA Jr., B. \& SAYD, J. D. Um mestrado para um momento preciso. Rio de Janeiro, UERJ/IMS, 1993 (Estudos em Saúde Coletiva, 47).

4.BIRMAN, J. A physis da saúde coletiva. Physis - Rev. Saúde Coletiva, 1 (1): 7-11. 1991.

5.BOJALIL, L. F. \& GARCIA, J. C. La Universidad Autónoma MetropolitanaXochimilco: consideraciones sobre el marco teórico de una práctica universitaria. México, UAM, Rectoria, 1981.

6.COHN, A. O social e sua incorporação no conhecimento e na prática médica. s.d. [mimeo].

7.COSTA, N. R. Política e projeto acadêmico: notas sobre a gênese do campo da saúde coletiva. Cad. de Hist. e Saúde, 2:125-36, 1992.

8.DONNANGELO, M. C. F. A pesquisa na área da saúde coletiva no Brasil. In: ABRASCO. Ensino de saúde pública, medicina preventiva e social no Brasil. Rio de Janeiro, 1982, p.4-19.

9.DONNANGELO, M. C. F. \& PEREIRA, L. Saúde e Sociedade. São Paulo, Duas Cidades, 1976.

10.FRANCO, A. S. La Salud al final del milenio. Cuad. Méd. Soc. (68):39-55, 1994. 
11.GARCÍA, J. C. La educación médica en América Latina. Washington, D. C., Organización Panamericana de la Salud, 1972.

12.LAURELL, A. C. El estudio social del processo salud-enfermedad en América Latina. Cuad Méd Soc (17):3-18, 1986.

13.MENENDÉZ, E. L. Salud pública: sector estatal, ciencia aplicada o ideologia de lo posible. In: Organization Panamericana de la Salud. La crisis de la salud pública: reflexiones para el debate. Washington, D. C., 1992, p.103-122.

14.NUNES, E. D. Tendências e perspectivas da investigação em ciências sociais e saúde na América Latina: uma visão geral. In: NUNES, E. D. org. Ciências Sociais e Saúde na América Latina: tendéncias e perspectivas. Brasília. OPAS. 1985, p.31-79.

15.NUNES, E. D. Trayectoria de la medicina social en América Latina: elementos para su configuración. In: Franco, S. et al. Debates en Medicina Social. Washington, D. C., OPS, 1991, p. 17-137.

16.ORGANIZATION PANAMERICANA DE LA SALUD. Enseñanza de la medicina preventiva y social - 20 años de experiencia latinoamericana. Washington, D. C. 1976.(OPS - Publ. Cient. 234).

17.PAIM, J. S. Desenvolvimento teórico-conceitual do ensino em saúde coletiva. In: ABRASCO. Ensino da saúde pública, medicina preventiva e social no Brasil. Rio de Janeiro, 1982, p. 4-19.

18.SIGERIST, H. E. Remarks on social medicine in medica education. In: ROEMER, M. HENRY E. Sigenist on the sociology of medicine. New York, MD Publications, Inc., 1960, p.360-8.

19.SILVA, G. R. Origem da medicina preventiva como disciplina do ensino médico. Rev. Hosp. de Clínicas Fac. Med., 28: 91-6, 1973. 